\title{
RYLE'S TUBE IN ABDOMEN: A RARE COMPLICATION OF ILLEGAL ABORTION.
}

Ashok Surybhanji Gajbhiye, Mangala M. Sonak, Jivan P. Shinde,

1. Assistant Professor. Department of General Surgery, IGGMC, Nagpur.

2. Assistant Professor. Department of General Surgery, GMC, Nagpur.

3. Assistant Professor. Department of General Surgery, IGGMC, Nagpur.

\section{CORRESPONDING AUTHOR:}

Ashok Surybhanji Gajbhiye,

Plot no- 54, Kalpatarunagar,

Manewada, Nagpur- 34.

E-mail: gsashok1972@gmail.com

ABSTRACT: One of the rare complications of abortion performed in rural area by a quack is being reported. Abortion was conducted with the help of Ryle's tube and this tube later on was found as foreign body in the abdominal cavity with rectal perforation. The Ryle's tube was removed by laparotomy and rectal injury was treated. Inspite of legalization of abortion in India, illegal abortion continues to be a major problem. Safe MTP should be made more popular and easily accessible. Till date, not a single case of uterine and rectal perforation by Ryle's tube has been reported in the literature.

KEYWORDS: Laparotomy: Colostomy: Rectal perforation: Abortion.

INTRODUCTION: Nearly 50-55 million induced abortion take place annually in the world today and half of these are still performed illegally ${ }^{1}$.

Illegal abortion has become an unusual problem in developed countries where legal abortion is allowed. It continues to be a major problem in third world countries where abortion is not yet legalized. Despite India being one of the first few countries to legalize abortion through MTP Act of 1971, it is unfortunate that we still see cases of illegal abortion here ${ }^{2}$.

The death rate from illegal abortion in developing countries is about 50-100 per $1,00,000$ procedures. Illegal abortion is 50-100 times more dangerous than any kind of contraceptive measure, depending on the age of the women and the method used ${ }^{3}$. Here we are reporting a rare operated case of Ryle's tube anthe abdomen due to illegal abortion.

CASE REPORT: Patient SBS, 18 yrs. unmarried girl residing at a remote village in Baitul district, Madhya Pradesh was admitted on 12/6/07 for recurrent shifting pain in abdomen for 2 months following abortion. On enquiry the patient disclosed that she went to a village quack in April 2007 when she had nearly 4 month amenorrhea and had an induced abortion. The quack attempted induction of abortion by introducing a tube like thing per vaginum. When the process was going on she had sudden severe pain. The quack then told her that the abortion process had completed and she could go home. She had moderate bleeding P/V for a few days. She had menstruated once. Later on she was having continuous pain in the abdomen associated with vomiting and fever. She consulted a doctor at Warud on 11/6/07, with c/o pain in the abdomen and scanty menses. On examination, he found that she had moderate general health with tenderness over lower quadrant of the abdomen. The patient was not willing for PV/PR examination.USG abdomen and X-ray abdomen and pelvis were done and she was referred to IGGMC, Nagpur on 11/6/2007 with diagnosis of peritonitis due to insertion of a plastic cannula 
for further management. Her abdomen was mildly tender and a hard elongated foreign body like substance was palpated in the right iliac fossa. Her USG and X-ray abdomen reports were not available and hence to confirm the diagnosis we repeated the investigations. X-ray abdomen and pelvis in standing position (fig-1) showed a linear long tubular radio-opaque shadow with three lead shots at the tip of the tube (Ryle's tube) in the abdominal cavity. USG abdomen (fig-2) revealed a tubular foreign body in the pelvis and periumbilical region with inflamed echogenic mesentery and adherent bowel loops and multiple pockets of loculated collection in the pelvis and right iliac fossa. Laparotomy was done after consulting a gynecologist. A Ryle's tube of number 20 with an intact cap was found lying in the abdominal cavity. After mobilizing the omentum it was found that the mouth end of the Ryle's tube with cap over it was seen perforating the rectum and the size of perforation was approximately $1 \times 1$ centimeter. Intraoperatively we could not find any uterine perforation or any scar on uterus. The reason behind it could be that the perforation might have sealed off following the perforation of uterus by the Ryle's tube or the tube might have directly perforated through the posterior fornix to enter the pouch of Douglas which could be the reason for the sudden severe pain and bleeding per vaginum in the patient. So the procedure was abandoned by the quack. Due to constant irritation of the dependent part, the rectum might have got perforated after few days of uterine perforation. The perforation was closed and proximal loop transverse colostomy was done. The

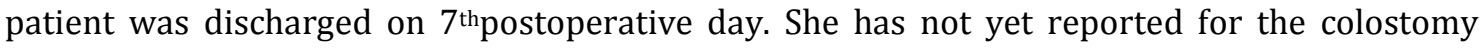
closure.

DISCUSSION: Till date, not a single case of uterine and rectal perforation by Ryle's tube has been reported in the literature. Only a case of Hegar dilator lying in the abdominal cavity without injury to bowel has been reported at NRS Medical College, Calcutta in a patient from a remote village in Puruliadistrict ${ }^{4}$.

In India, the main reasons for illegal abortion are the social stigma associated with unmarried status and lack of education in rural areas. Besides, quacks are easily available in the vicinity of patients. They charge very less and are easily affordable. So the women can avoid expensive MTP in authorized private health centers or the long queues in Government hospitals. But it comes at a great cost which can jeopardize the health of women seriously and can even be fatal ${ }^{5}$.

Hence, in spite of legalization of abortion in India, illegal abortion continues to be a major problem. Safe MTP should be made more popular and easily accessible to the pregnant ladies to avoid the sequelae of illegal abortion.

\section{REFERENCES:}

1. Sinha R, Bara MM. Maternal mortality in unsafe abortion. J. Obst. \& Gyn. of India, March/April 2001; 51(2): 123-125.

2. Padubidri V.G, Daftary S.N. Abortion. Howkins andBourne Shaws Textbook of

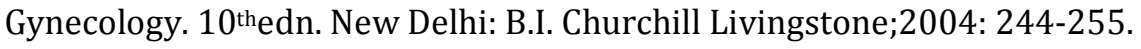

3. Chaudhuri. S.K. and international contributors.Pregnancy termination,Practice of

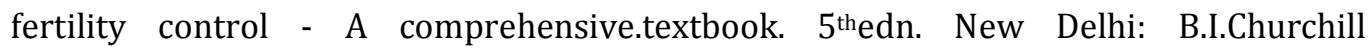
Livingstone;2001: 229 - 260.

4. Mukhopadhya G, Bhattacharya N.Dilator in Abdomen-A rare complication of criminal abortion. J. of Obst. \& Gyn. of India.March/April2002; 52 (2):114. 


\section{ORIGINAL ARTICLE}

5. Kaur M, Mathur A.K. Serious Injury to uterus and sigmoid colon in MTP.J. of obst \& Gyn. of India. May/June 2002; 52 (3): 110.

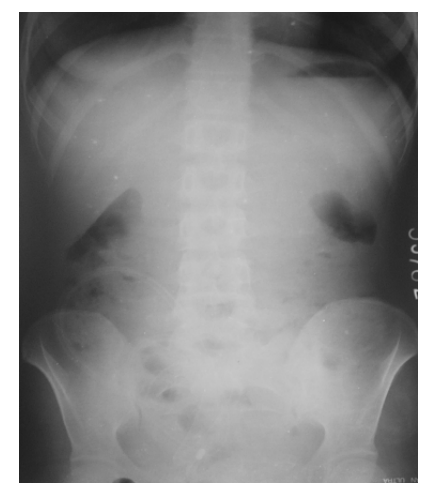

FIG-1] X-RAY ABDOMEN AND PELVICE RYLES TUBE IN ABDEMEN( S/O BODYAIND S S/O TIP OF RYLES TUBE)
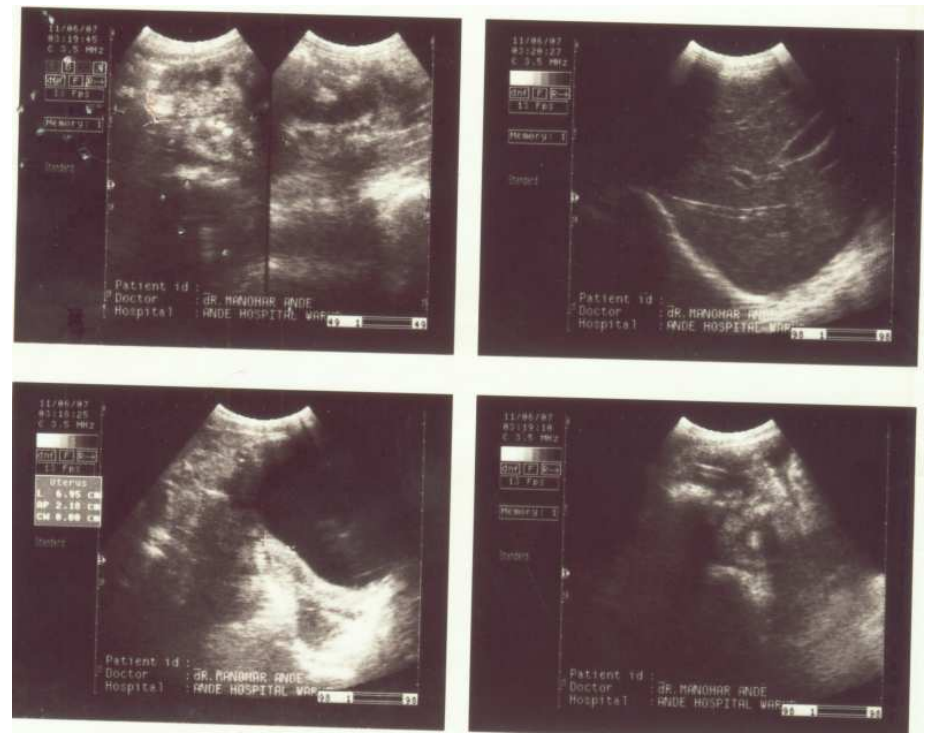

FIG-2 ULTRASONOGRAPHY ABDOMEN AND PELVIS (RYLES TUBE IN ABDOMEN) 